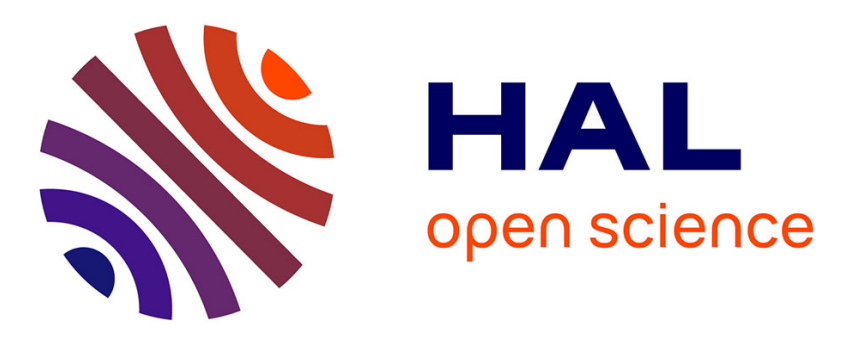

\title{
Microstructure and mechanical properties of high strength steel deposits obtained by Wire-Arc Additive Manufacturing
}

Clément Bourlet, Sandra Zimmer-Chevret, Raphaël Pesci, Régis Bigot, Aurélien Robineau, Fabrice Scandella

\section{To cite this version:}

Clément Bourlet, Sandra Zimmer-Chevret, Raphaël Pesci, Régis Bigot, Aurélien Robineau, et al.. Microstructure and mechanical properties of high strength steel deposits obtained by WireArc Additive Manufacturing. Journal of Materials Processing Technology, 2020, 285, pp.116759. 10.1016/j.jmatprotec.2020.116759 . hal-02894980

\section{HAL Id: hal-02894980 https://hal.science/hal-02894980}

Submitted on 9 Jul 2020

HAL is a multi-disciplinary open access archive for the deposit and dissemination of scientific research documents, whether they are published or not. The documents may come from teaching and research institutions in France or abroad, or from public or private research centers.
L'archive ouverte pluridisciplinaire HAL, est destinée au dépôt et à la diffusion de documents scientifiques de niveau recherche, publiés ou non, émanant des établissements d'enseignement et de recherche français ou étrangers, des laboratoires publics ou privés. 


\title{
Microstructure and mechanical properties of high strength steel deposits obtained by Wire-Arc Additive Manufacturing
}

\author{
Clément Bourlet ${ }^{\mathrm{a}, \mathrm{b}, \mathrm{c}, *}$, Sandra Zimmer-Chevret ${ }^{\mathrm{b}}$, Raphaël Pesci ${ }^{\mathrm{c}}$, Régis Bigot ${ }^{\mathrm{b}}$, \\ Aurélien Robineau ${ }^{\mathrm{a}}$, Fabrice Scandella ${ }^{\mathrm{a}}$ \\ ${ }^{a}$ Institut de Soudure, 4 Boulevard Henri Becquerel, 57970 Yutz, France \\ ${ }^{\mathrm{b}}$ Arts et Métiers ParisTech, Université de Lorraine, LCFC, 4 rue Augustin Fresnel, 57078 Metz Cedex 3, France \\ ${ }^{\text {c }}$ ENSAM-Arts et Métiers ParisTech, LEM3 UMR CNRS 7239, 4 rue Augustin Fresnel, 57078 Metz Cedex 3, France
}

\begin{abstract}
A B S T R A C T
Wire-arc additive manufacturing has become an alternative way to produce industrial parts. In this work $15 \mathrm{~kg}$ walls are built with an effective building rate of $4.85 \mathrm{~kg} / \mathrm{h}$ using an ER100 wire providing good tensile properties and toughness under welding conditions. The thermal evolution of the walls during manufacturing is measured by thermocouples and an IR camera: it depends on process parameters, deposit strategy and the size of the part. The walls are then characterised as deposit and after heat treatment through hardness, tensile and Charpy-V notch tests. The results show a fine microstructure with unexpected retained austenite and coarse allotriomorphic ferrite in the as deposited walls. The final hardness values vary from about 220 to $280 \mathrm{HV} 2$; the yield stress and tensile strength are 520 and $790 \mathrm{MPa}$, respectively, and a toughness of about $50 \mathrm{~J}$ is obtained at room temperature. The heat treatment transforms the retained austenite, leading to an improvement of the yield stress to $600 \mathrm{MPa}$.
\end{abstract}

\section{Introduction}

The Additive Manufacturing (AM) technologies encountered so much enthusiasm since the apparition of the first 3D printers that the landscape definitely changed and the range of possibilities extended: new ideas have emerged in the recent years with AM processes able to produce metallic parts from powder, wire or sheet. The major difference with other conventional manufacturing processes such as casting, forging or machining is that AM adds material layer by layer, is tool free and can produce parts with geometries not easily obtained through other processes. There are many works in literature on miscellaneous AM processes using either laser, electron beam or an electrical arc as heat sources. On the one hand, powder bed fusion (PBF) uses laser or electron beam to melt very thin layers of powder (less than $100 \mu \mathrm{m}$ ): it is possible to manufacture very complex parts but with limited size (around $400 \times 400 \times 400 \mathrm{~mm}^{3}$ ). Manufacturing time is very high since many layers need to be deposited. On the other hand, direct energy deposition (DED) uses laser, electron beam or an electrical arc to create a melt pool from powder or wire. Ding et al. (2015a) compared PBF and powder-DED to wire-DED and showed that wire-DED has a higher build rate that enables to produce large yet simple parts at lower costs.
However, the surface finish obtained only enables near net shape parts to be produced and requires final machining or grinding. Moreover, laser or electron beam devices are expensive and require a lot of time compared to wire-arc AM: they should be rather used for the manufacture of high added value parts.

A typical wire-arc AM machine is composed of a robot and a welding device (Williams et al., 2016). Wire-arc AM is a wire-DED process to build parts by stacking layers of beads thanks to an electric arc which melts a wire: each layer can be composed of one or multiple overlapped beads. It can also be used to add features on existing parts coming initially from casting or forging (Hirtler et al., 2018) and to produce large parts for aerospace (Williams et al., 2016), naval (Shen et al., 2018), power generation (Appleyard, 2012) and other industrial applications (Yili et al., 2018). Beside the process itself, the material properties and the microstructure obtained have also been investigated on titanium alloys using gas tungsten arc welding (GTAW) (Wang et al., 2013) or plasma (Lin et al., 2016), aluminium using GTAW (Qi et al., 2018) or gas metal arc welding (GMAW) (Gu et al., 2014), nickel-based alloys using GMAW (Xu et al., 2019) and stainless steel such as 17-4PH (Caballero et al., 2019) or 316 L (Chen et al., 2017). High strength steels are fairly common materials in industry, but only a few data is available 


\section{Nomenclature}

AM Additive Manufacturing

PBF Powder Bed Fusion

DED Direct Energy Deposition

GTAW Gas Tungsten Arc Welding

GMAW Gas Metal Arc Welding

CMT Cold Metal Transfer

Wfr Wire feed rate
Trs Travel speed

d distance between beads

w bead width

a overlap coefficient

Lw Layer width

Ys $\quad$ Yield strength

Ts Tensile strength

A\% $\quad$ strain to fracture regarding wire-arc AM. As steel is cheap, one explanation for this is the low economic viability of AM compared to titanium or nickel alloy parts. However, wire-arc AM does not require the use of manufacturing tools compared to forging or casting that are expensive in case of very small series or prototypes for steel parts: it could be a good alternative to reduce the lead time or the overall cost in that case.

In the literature, microstructure and mechanical properties are mostly studied in thin walls composed of only one bead width since thick walls are often more complicated to build due to bead overlapping. The characterisation of such thin walls may not be representative of industrial parts so that some authors as Ding et al. (2015b) developed some models to obtain stable deposits and regular overlapping beads leading to an optimal distance between the centre of each bead equal to 0.738 times the bead width.

However, most of the models don't take into account the temperature of the part. Heat input during manufacturing is a key parameter leading to material temperature rise, residual stresses and part distortion, or drift in the process. Ding et al. (2011) investigated this effect on a long wall using a finite element model and showed the stress redistribution and part distortion after unclamping. Bai et al. (2016) described the thermal cycle induced by material deposition and explained resulting microstructures. Wu et al. (2017) used an infrared pyrometer to measure temperature on deposits leading to a more precise interpass temperature compared to using a thermocouple fixed on the substrate. They claimed that the interpass temperature should be strictly controlled to improve process stability during deposition of Ti6Al4V. It appears important to monitor the temperature to understand the thermal evolution during fabrication and then the resulting microstructure and mechanical properties.

Considering the economic model of wire-arc AM as proposed by Martina and Williams (2015), it is possible to show that for low cost materials, the price of the part mainly depends on manufacturing cost and not material cost. Thus, in order to make wire-arc AM competitive, manufacturing time necessarily needs to be reduced, so that the use of a high deposition rate process is a good solution. Tabernero et al. (2018) obtained stainless steel and titanium parts at a deposition rate of $5 \mathrm{~kg} / \mathrm{h}$ and $2.5 \mathrm{~kg} / \mathrm{h}$, respectively; Martina et al. (2018) achieved a deposition rate of $9.7 \mathrm{~kg} / \mathrm{h}$ with tandem GMAW using stainless steel wire. Most of the time, the deposition rate calculation is only based on wire feed rate (Wfr), which means that the cooling time between layers or the arc off time (waiting time) are not considered. To take into account the arc off time, it is possible to define the deposition time efficiency as the ratio of arc on time over complete manufacturing time (arc on + arc off times).
The effective building rate, corresponding to the deposition time efficiency multiplied by the deposition rate, is more useful to estimate both part price and manufacturing time. In fact, the deposition time efficiency is close to 1 in case of very large parts (with few stops) or if multiple parts are built simultaneously (parts built while others are cooling).

The present work investigates the ER100 steel properties deposited using wire-arc AM with the Cold Metal Transfer (CMT) GMAW process. Manufacturing parameters were evaluated on preliminary workpieces (100 mm length, 4 beads width, 20 layers height) and selected if no internal defect was found. Then, in order to be representative of fairly large forged or cast industrial parts, walls over $20 \mathrm{~mm}$ thick, $380 \mathrm{~mm}$ long and $180 \mathrm{~mm}$ high were produced. This represents about $15 \mathrm{~kg}$ of steel deposited with deposition time efficiency close to 1 , as arc on time was maximised. The temperature of walls was recorded during manufacturing using both thermocouples and infrared (IR) camera. The resulting microstructure and mechanical properties were investigated and correlated to the thermal fields. The effect of a final heat treatment on these properties was finally studied.

\section{Experimental procedure}

\subsection{Materials and equipment}

The consumable used is a commercial high strength steel ER100 (according to AWS A5.28) or G 696 M21 Mn4Ni1.5CrMo (according to ISO 16834) wire $1.2 \mathrm{~mm}$ in diameter. The substrate is a $20 \mathrm{~mm}$ thick S355 steel plate, $500 \mathrm{~mm}$ long and $100 \mathrm{~mm}$ wide. Before deposition, plates were ground, cleaned with acetone and clamped at each corner. The chemical composition of both steels is provided in Table 1.

Wire-arc AM was performed using a KR30 Kuka robot with a Fronius TPS4000 welding device (Fig. 1). The selected CMT synergy law was $\mathrm{C} 1640$ with an $\mathrm{Ar}$ and $18 \% \mathrm{CO}_{2}$ shielding gas set at a flow rate of $16 \mathrm{l} / \mathrm{min}$. The working distance (between contact tip and part) was $15 \mathrm{~mm}$.

\subsection{Methodology}

\subsubsection{Deposition path}

The deposit path was defined according to the wall geometry and process parameters. Here, the walls had a rectangular section and were built with a parallel bead strategy along the wall length. The distance between beads "d" represented in Fig. 2a is defined by $d=a$ * w, "a"

Table 1

Chemical composition of raw materials (wt.\%) coming from material certificates provided by Selectarc Welding (wire) and Thyssenkrupp Materials (substrate).

\begin{tabular}{|c|c|c|c|c|c|c|c|c|c|c|c|}
\hline \multicolumn{12}{|c|}{ ER100 (Wire) } \\
\hline 0.08 & 0.54 & 1.66 & 0.25 & 1.58 & $\begin{array}{c}0.47 \\
\text { S } 35\end{array}$ & $\begin{array}{c}0.007 \\
\text { rate) }\end{array}$ & 0.01 & 0.002 & 0.05 & 0.14 & Bal. \\
\hline C & $\mathrm{Si}$ & $\mathrm{Mn}$ & $\mathrm{Ni}$ & Mo & $\mathrm{P}$ & S & $\mathrm{V}$ & N2 & $\mathrm{Al}$ & $\mathrm{Cu}$ & $\mathrm{Fe}$ \\
\hline 0.162 & 0.016 & 1.507 & 0.012 & 0.002 & 0.02 & 0.006 & 0.002 & 0.003 & 0.041 & 0.023 & Bal. \\
\hline
\end{tabular}




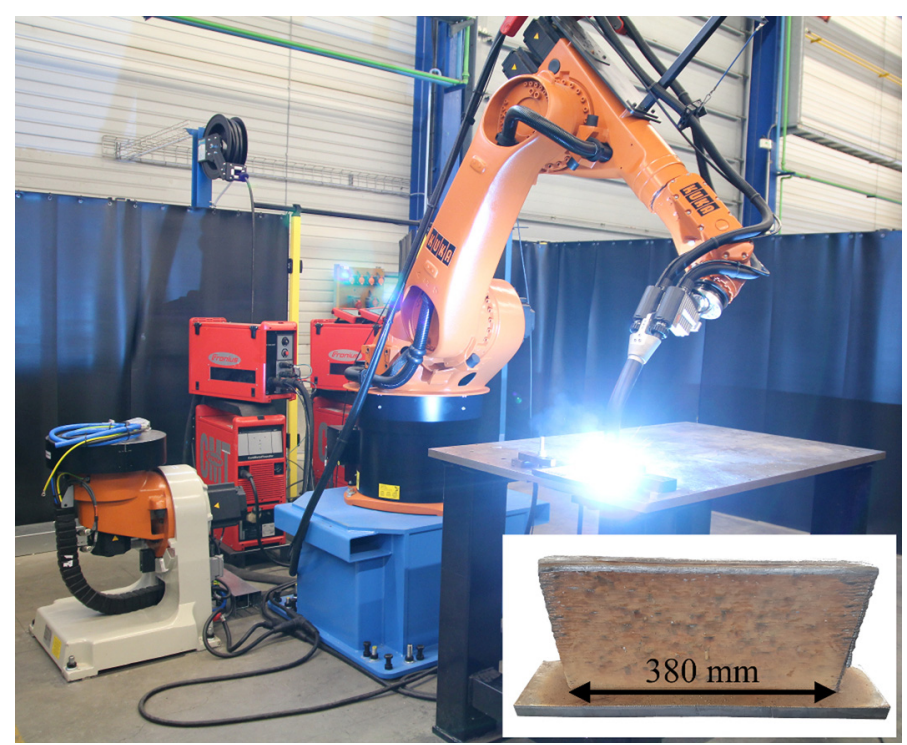

Fig. 1. Experimental set-up for wire-arc AM and manufactured part.

being the overlap coefficient (i.e. 0.738 as defined by Ding et al. (2015b)). With this strategy, layers width (Lw) was defined as $\mathrm{Lw}=\mathrm{w}^{*}(1+(\mathrm{N}-1) * \mathrm{a})$, "N" being the numbers of beads in a layer. The chosen parameters led to a single bead width between 6 and $10 \mathrm{~mm}$. To obtain a layer width of $20 \mathrm{~mm}$, the chosen number of beads in a layer, $\mathrm{N}$, was 4 . The deposition path is showed in Fig. 2b with alternated layers to reduce height variations induced by ignition and extinction of the arc.

\subsubsection{Selection of process parameters}

The main goal of this work is to characterize the microstructure and mechanical properties of the ER100 on large parts. In order to limit the risk of defect during the fabrication of walls, a selection of process parameters is carried out following this method:

- Step 1: deposition of $100 \mathrm{~mm}$ long single beads. Irregular beads were not used for step 2 .

- Step 2: deposition of preliminary workpiece composed of 20 layers with a path length of $100 \mathrm{~mm}$ and an interlayer temperature of $50^{\circ} \mathrm{C}$. Wfr of $5,7.5$ and $10 \mathrm{~m} / \mathrm{min}$ with Trs ranging from 20 to
$100 \mathrm{~cm} / \mathrm{min}$ were investigated. The quality of the deposit was assessed on three cross-sectional macrographs and only process parameters not leading to defects visible at a magnification of $\mathrm{x} 10$ were considered able to manufacture large walls.

The results in green in Fig. 3 correspond to acceptable process parameters according to Step 2 whereas those in red lead to prohibitive defects, the most visible originating from low Wfr or high Trs. Low Wfr $(5 \mathrm{~m} / \mathrm{min})$ produced a lot of inclusions, which were located between beads in each layer and the size of which ranges from $0.1 \mathrm{~mm}$ up to $1 \mathrm{~mm}$. The location of these inclusions suggests that there was not enough heat to re-melt it. For high Trs, the melt pool length increased and became irregular, leading to other defects such as lack of fusion and bad wall geometry.

Finally, selected parameters were $\mathrm{Wfr}=10 \mathrm{~m} / \mathrm{min}$ and Trs $=80 \mathrm{~cm} / \mathrm{min}$ so as to obtain wall widths close to $20 \mathrm{~mm}$ and to reach a higher deposition rate $(\mathrm{Wfr}=10 \mathrm{~m} / \mathrm{min}$ lead to $5.3 \mathrm{~kg} / \mathrm{h}$ ) compared to other AM processes such as PBF (from 0.04 to $0.5 \mathrm{~kg} / \mathrm{h}$ ) or powder-DED (from 0.12 to $1.8 \mathrm{~kg} / \mathrm{h}$ ); each layer deposition took $115 \mathrm{~s}$ plus a dwell time of $10 \mathrm{~s}$, which lead to a deposition time efficiency of $92 \%$ (close to

(a)
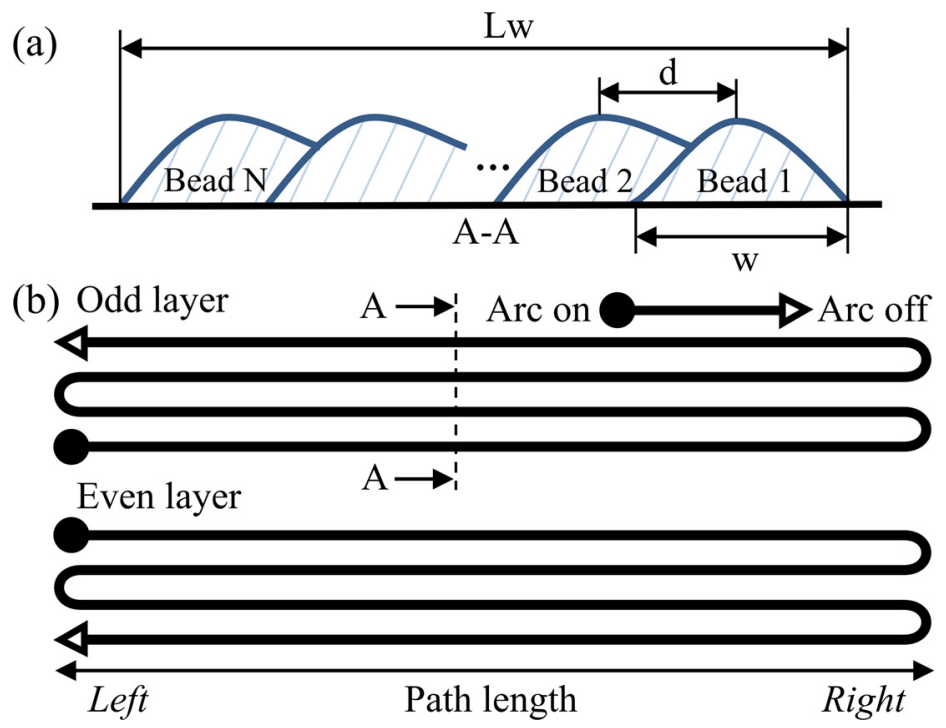

Fig. 2. Deposit strategies: (a) cross section of layers, (b) tool path for layers. 


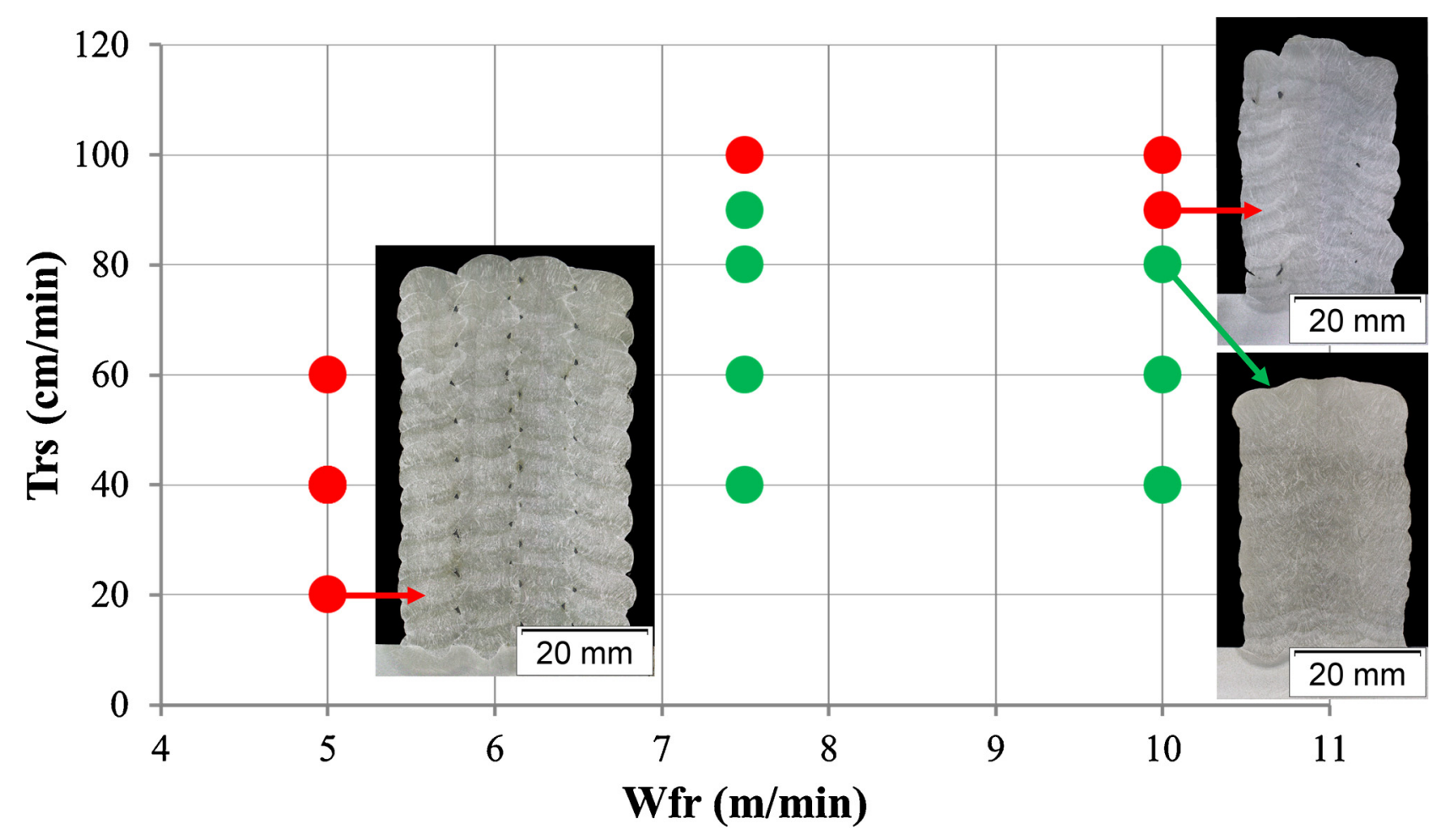

- No visible defect $\bullet$ With defects

Fig. 3. Process parameters with final operating range obtained for a preliminary workpiece.

1).

\subsection{Wall manufacturing}

\subsubsection{Thermal monitoring}

As the deposition time efficiency is close to 1 , the temperature of the wall is difficult to estimate and needs to be measured. To monitor the temperature during wall manufacturing, K-type thermocouples were used on both the substrate and the wall during build-up (Fig. 4). Three thermocouples were welded under the substrate prior to fabrication in the middle, the $3 / 4$ and the end of the deposition path. Other thermocouples were directly inserted in the melt pool during deposition to measure local thermal cycles. The IR camera was used to measure the thermal field of the entire wall during manufacturing: the emissivity was adjusted to obtain a good matching between the temperature measured by the thermocouples and that provided by the IR camera.

\subsubsection{Wall characterization}

Specimens were extracted from each wall for tensile, toughness (Charpy V-notch) and hardness tests, as well as microstructure examination (Fig. 5). Tensile specimens were extracted along the deposit direction (horizontal specimens $\mathrm{H}$ ) at several heights, and across layers (vertical specimens $\mathrm{V}$ ) to check for possible anisotropy. The dimensions of the tensile test specimens are in accordance with ISO 6892-1 standard. Tests were carried out at room temperature with a strain rate of $10^{-3} \mathrm{~s}^{-1}$. Microhardness measurements were performed using an automatic Vickers hardness-testing machine (2 kg load and indentation time of $10 \mathrm{~s}$ ); hardness maps were obtained on cross-sections of walls with a step of $2 \mathrm{~mm}$ in both directions. Toughness specimens were standard $10 \mathrm{~mm}$ Charpy V-notch (according to ISO 148-1) extracted at three different heights in the wall. Prior tests at $-60^{\circ} \mathrm{C}$ were performed on vertical and horizontal Charpy specimens: the different notch orientations did not show any difference in term of values and failure mode, so that it was decided to focus only on vertically-oriented notches to get enough specimens for a good reproducibility, as shown in Fig. 5, and testing temperatures ranging from -60 to $20^{\circ} \mathrm{C}$ with $20^{\circ} \mathrm{C}$ steps to determine the ductile-to-brittle transition curve. Metallographic specimens were extracted from cross-sections of the walls. All specimens were ground, polished and etched with 3\% nital and Klemm's reagent, which is composed of $50 \mathrm{ml}$ water saturated with sodium thiosulfate $\left(\mathrm{Na}_{2} \mathrm{~S}_{2} \mathrm{O}_{3}\right)$ and $1 \mathrm{~g}$ of potassium metabisulfite $\left(\mathrm{K}_{2} \mathrm{~S}_{2} \mathrm{O}_{5}\right)$ (Vander Voort, 2004). A PROTO goniometer was used to estimate the volume fraction of retained austenite according to ASTM E975-13 standard. A chromium X-ray tube ( $\lambda=2.2897 \AA$ ) with a $2 \mathrm{~mm}$ diameter collimator has been used to acquire peaks corresponding to $\{200\}$ and $\{211\}$ planes for BCC phases and $\{200\}$ and $\{220\}$ planes for FCC austenite. The volume fraction of retained austenite $\left(V_{\gamma}\right)$ was calculated with the following equation: (ASTM E975-13, 2013)

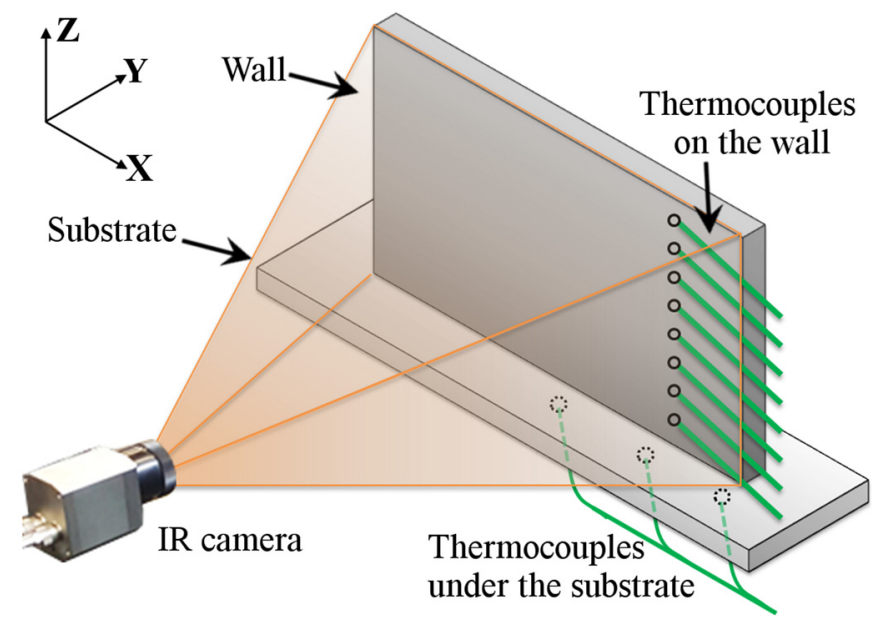

Fig. 4. Drawing showing the position of the IR camera and thermocouples. 


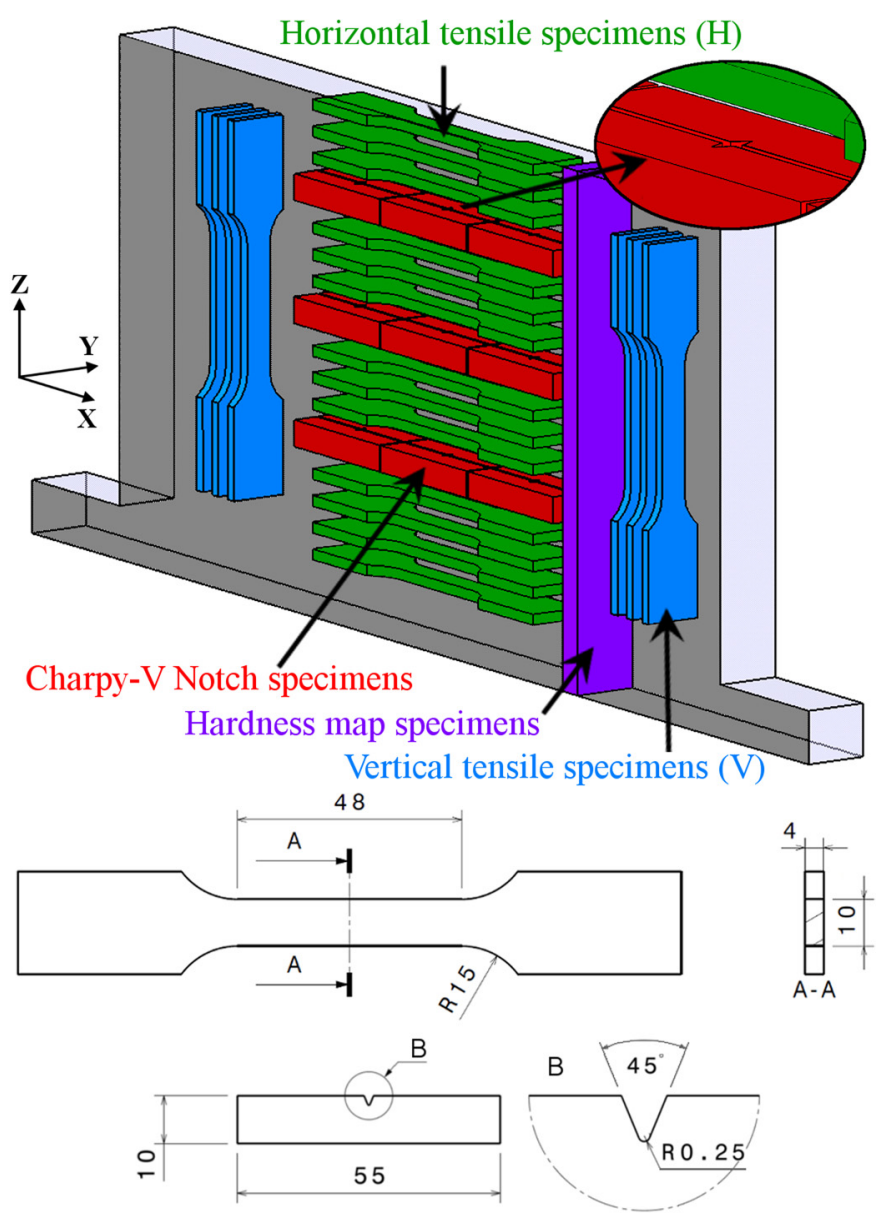

Fig. 5. Position and dimensions of specimens for hardness, tensile and Charpy tests.

$V_{\gamma}=\left(\frac{1}{q} \sum_{j=1}^{q} \frac{I^{\gamma j}}{R^{\gamma j}}\right) /\left(\frac{1}{p} \sum_{i=1}^{q p} \frac{I^{\alpha i}}{R^{\alpha i}}\right)+\frac{1}{q} \sum_{j=1}^{q} \frac{I^{\gamma j}}{R^{\gamma j}}$

where $I^{\alpha i}$ and $I^{\gamma i}$ are the diffraction peak intensities of BCC phases and austenite, respectively. $R^{\alpha i}$ and $R^{\gamma i}$ coefficients depend on the structure, the Lorentz Polarization, the Debye-Waller and the multiplicity of the considered $\{\mathrm{hkl}\}$ reflection factors.

This method allowed to produce two walls over $20 \mathrm{~mm}$ thick, $380 \mathrm{~mm}$ long and $180 \mathrm{~mm}$ high. This represents about $15 \mathrm{~kg}$ of steel per wall. After manufacturing, one of walls was heat-treated at $600{ }^{\circ} \mathrm{C}$

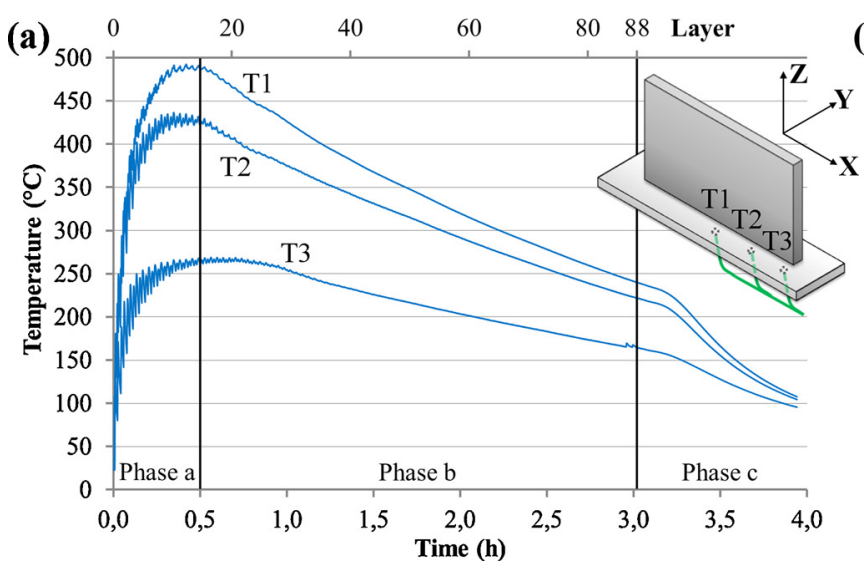

during 4 hours with heating and cooling rate of $50{ }^{\circ} \mathrm{C} / \mathrm{h}$ to assess the effect of stress releasing treatment upon material, microstructure and mechanicals properties.

\section{Results and discussion}

\subsection{Temperature monitoring}

\subsubsection{Temperature in the substrate}

Temperatures recorded under the substrate are shown in Fig. 6. The maximum temperature reached by each thermocouple depends on the position along the wall. As can be seen in Fig. 6, thermocouple T1 reaches the highest temperature in each wall; the central region increases in temperature and also remains hotter than the edges. Moreover, the manufacturing of several walls shows similar temperature profiles in the substrate with a good thermal repeatability of the process.

All substrate thermal cycles can be divided into three phases as described in Fig. 6a:

- Phase a corresponds to a quick rise in temperature for the deposition of approximately the first 15 layers. During this phase, the heat brought by the arc is mostly dissipated by conduction and accumulated in the substrate. The saw teeth-like profile is due to successive passages of electric arc. This can be clearly seen in Fig. $6 \mathrm{~b}$, which shows that the top of each peak is reached when the arc is closest to the thermocouple.

- Phase $\mathrm{b}$ is the progressive cooling down. Once several layers have been deposited and during the rest of the fabrication, heat is increasingly dissipated by convection through the wall side as the height of the wall increases, resulting in less heat being transmitted to the substrate. As the distance between the arc and thermocouples increases during manufacturing, the temperature variations in the substrate are dampened.

- Phase $\mathrm{c}$ is a faster cooling down at the end of the fabrication. When the wall is finished, the electrical arc is stopped and no more heat is brought at the top of the wall. The temperature of the wall decreases and becomes more uniform. Thanks to the heat accumulated in the wall, a delay of approximately 15 minutes is observed between the arc switching off and the change of slope on the curves.

However, the temperature measured by thermocouple in the substrate does not reflect the temperature in the deposits. That is why it is important to study the global temperature of the wall layer by layer.

\subsubsection{Temperature distribution in the wall}

Fig. 7 shows images from the IR camera at 25, 50, 75\% of wall

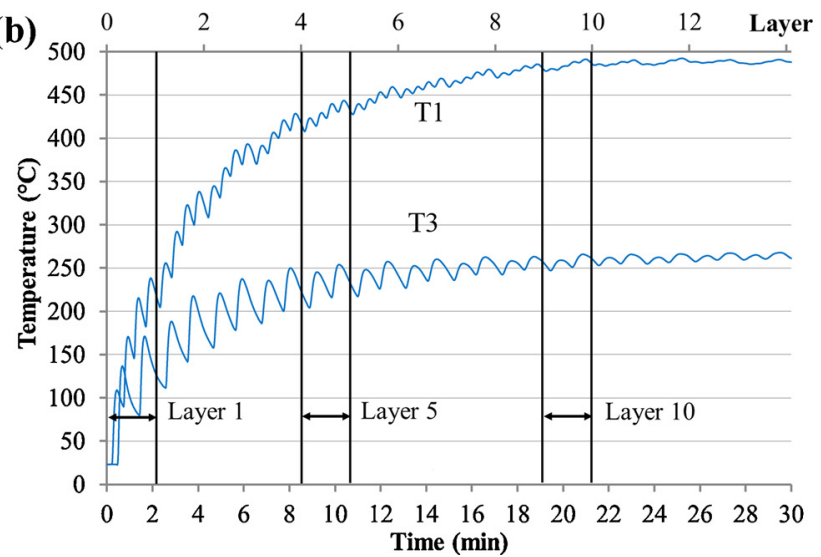

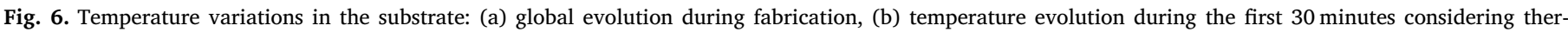
mocouples 1 and 3 . 


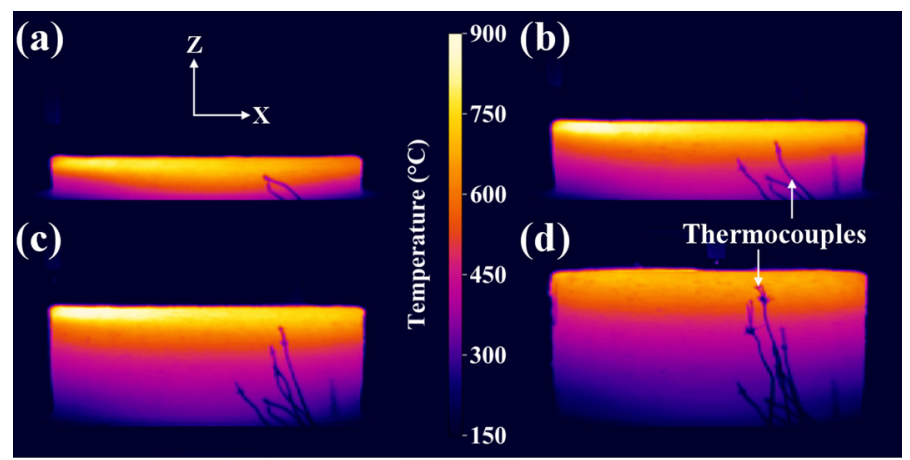

Fig. 7. Thermal field on one side of the wall after (a) 22 layers (25\%), (b) 44 layers (50\%), (c) 66 layers (75\%), (d) 88 layers (100\% of the fabrication). Note: features in black are thermocouples.

build-up and at the end of the fabrication. The temperature along the wall (X-axes corresponding to deposition direction) is fairly homogenous and the temperature gradient is along Z-axes.

Beside the IR camera, 8 thermocouples inserted in the melt pool were used to monitor the temperature on the wall. Fig. 8a presents the temperature acquisition of the 8 thermocouples and Fig. $8 \mathrm{~b}$ their approximated locations in the wall. The first peak of each recording corresponds to thermocouple insertion. Since the thermocouple is melted inside the melt pool, the first temperature recorded is around $1400^{\circ} \mathrm{C}$. Thanks to this, it is possible to know the instantaneous temperature at different heights on the wall. No interpass temperature was set: a dwell time about $10 \mathrm{~s}$ was chosen between successive layers in order to allow IR camera data to be recorded. Consequently, the wall reaches very high temperature, as can be seen in Fig. 8a. The maximum temperature at the top of the wall measured just before arc on by the IR camera is represented by the grey line with a $+/-50^{\circ} \mathrm{C}$ uncertainty coming from the fast cooling rate at high temperature combined with the precision and the position of the camera. This inter-layer temperature gradually increases to $750{ }^{\circ} \mathrm{C}$ for thermocouples placed on layers 11,15 and 26 and remains fairly constant for all other thermocouples. Temperature recordings of thermocouples on layer 26 to 72 are very similar above $600{ }^{\circ} \mathrm{C}$. For the last layers, the temperature recorded by the thermocouple on layer 84 does not remain hot (over $600{ }^{\circ} \mathrm{C}$ ) for a long time since the fabrication ends soon after deposition.

In order to understand the temperature variations, it is interesting to study more precisely the temperature recorded by one thermocouple. Fig. 9 shows the temperature recording of thermocouples placed on layer 36. Some measurement noise was observed during wall build-up due to the magnetic field generated by the electric arc. The temperature varies depending on the location of the electric arc with respect to the thermocouple. Different events have been marked in Fig. 9 which correspond to the following:

- a: the thermocouple is inserted in the melt pool.

- b: the temperature decreases, layer 36 is finished and layer 37 starts. - c: the temperature rises as the electric arc gets close to the thermocouple and then decreases.

- d: the temperature rises again but reaches a lower value as the electric arc passes further away from the thermocouple.

- e and f: as for $\mathrm{d}$.

- g: layer 37 is finished, layer 38 starts.

- $\mathrm{h}$ and $\mathrm{i}$ : the temperature rises and reaches a higher value since the electric arc comes close to the thermocouple.

- $\mathrm{j}$ : the electric arc comes close to the thermocouple, but the temperature reached is lower than in a and c since the electric arc is one layer above.

- After j: a new cycle starts but maximum temperatures are always lower since the electric arc moves away from the thermocouple.

Each thermal cycle is thus dependent of the thermocouple position (a)

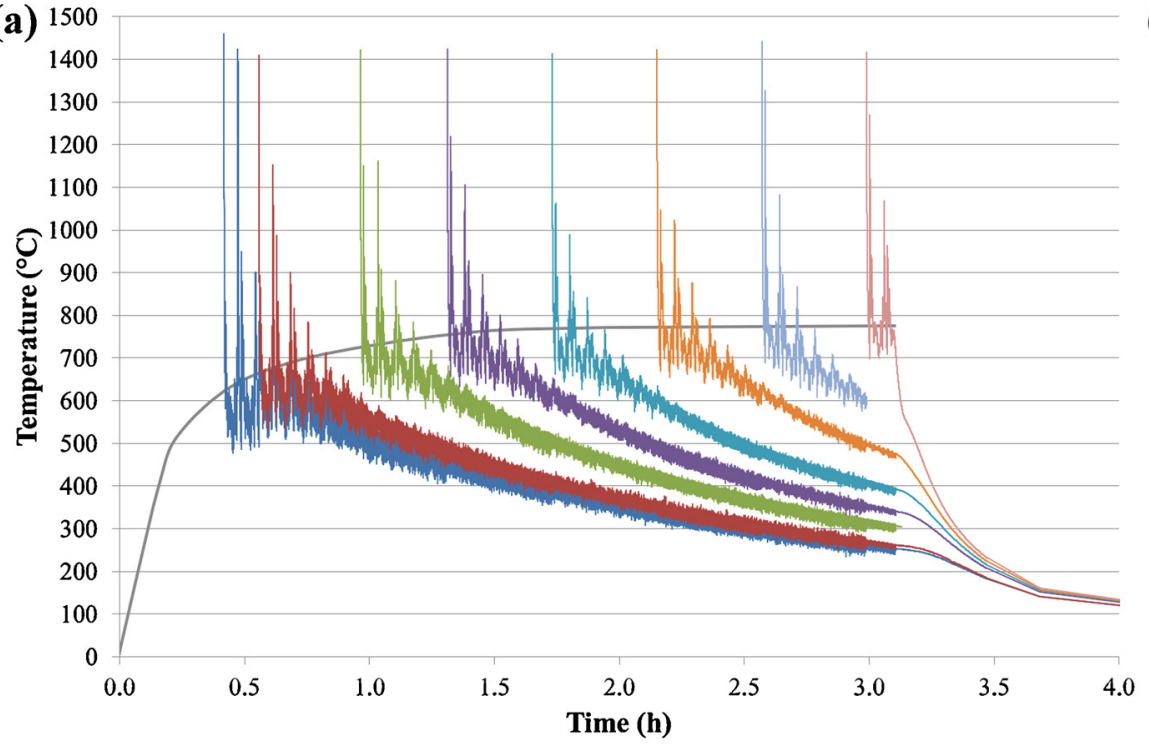

(b)

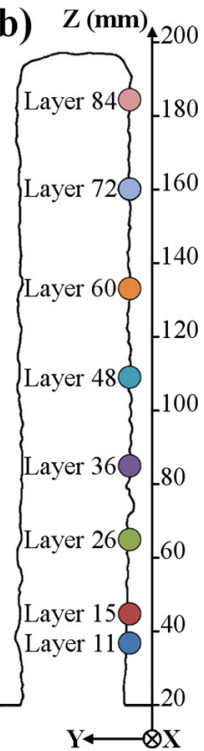

Fig. 8. (a) Temperature recording obtained with 8 thermocouples placed on one side of the wall, (b) cross section of the wall showing the location of the thermocouples. Note: the grey area corresponds to the evolution of the temperature given by the IR camera at the top of the wall. 


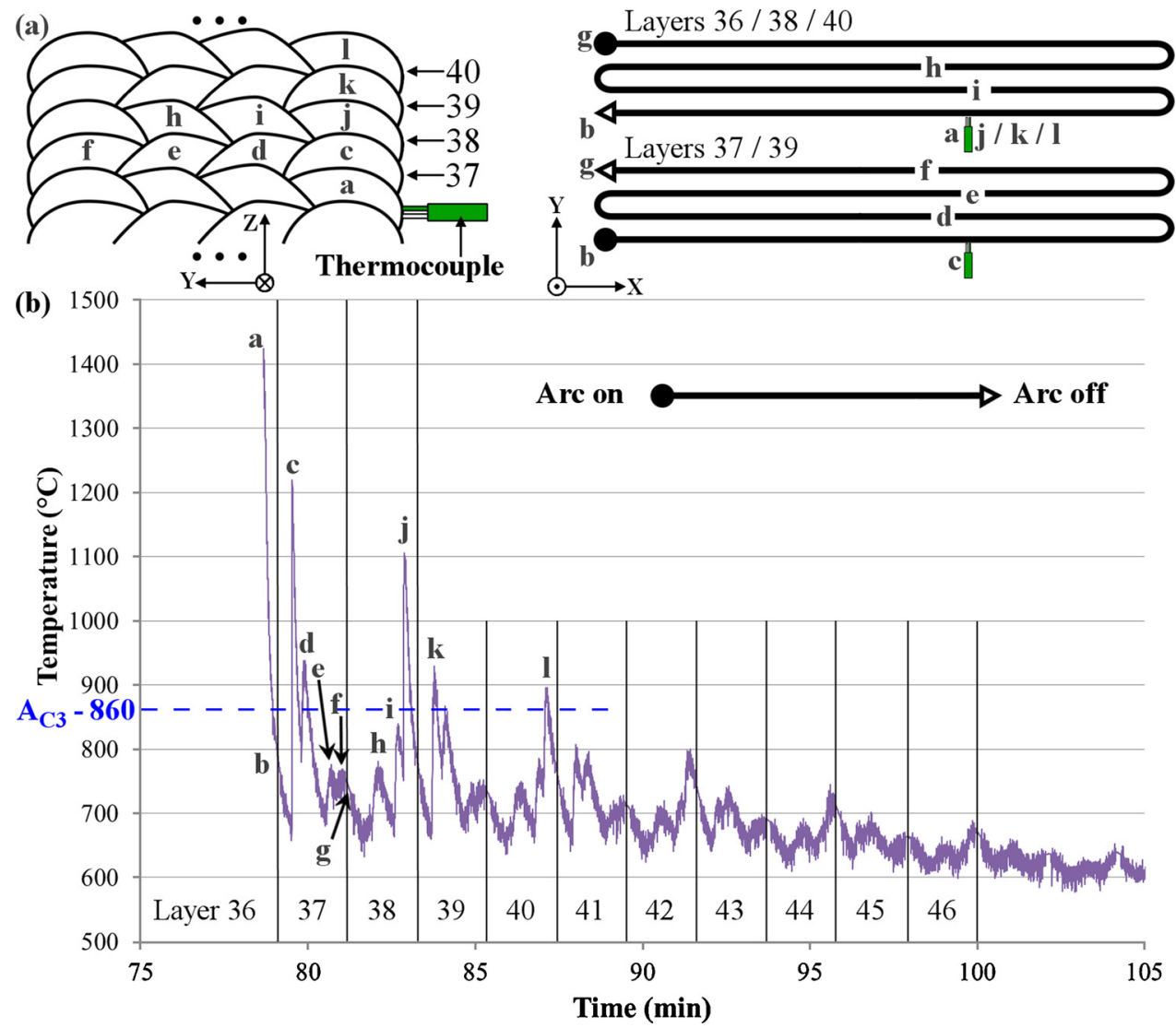

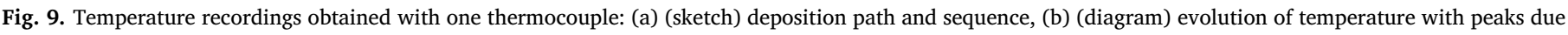
to arc passes near thermocouple.

with respect to the electric arc as well as the manufacturing strategy. Moreover, results show that layer 36 is reheated above $860^{\circ} \mathrm{C}\left(\mathrm{A}_{\mathrm{C} 3}\right.$ determined for this ER100 material by dilatometry) when four subsequent layers are deposited. Moreover, this region of the wall remains above $600{ }^{\circ} \mathrm{C}$ for about 30 minutes. This time spent above $600{ }^{\circ} \mathrm{C}$ is due to both the high inter-layer temperature and the deposition of many subsequent layers. Consequently, layers with this temperature evolution are in the middle of the wall from approximately layers 25 to 73 .

Though the temperature is fairly homogenous at the top of the wall once several layers have been deposited, locally, the thermal cycle is very complex. Thanks to the temperature measurement, the relation between the temperature evolution and the deposition strategies is understood. It can also be concluded that each layer has its own thermal history but it is possible to define 3 zones with equivalent thermal evolution:

- Bottom: the first layers are deposited on a substrate or a layer with low initial temperature. These layers do not get very hot for long.

- Middle: layers located in the middle of the wall reach high interlayer temperature (about $750{ }^{\circ} \mathrm{C}$ ) and stay over $600{ }^{\circ} \mathrm{C}$ during approximately 30 minutes.

- Top: the last deposited layers also reach high temperatures but do not remain above $600{ }^{\circ} \mathrm{C}$ for a long time since the fabrication ends.

The effect of those different thermal conditions in the wall on the microstructure and then on the mechanical properties are important to study. Microstructure and mechanical properties are studied on two walls: one as deposited and another heat-treated.

\subsection{Microstructure}

\subsubsection{Wall microstructure in the as deposited conditions}

In the previous section, three zones with different thermal conditions were defined at the bottom, the middle and the top of the wall. Fig. 10 presents a cross sectional macrograph at low magnification at (a) the bottom, (b) the middle and (c) the top of the wall. The microstructures at the bottom (Fig. 10a) and the top (Fig. 10c) of the wall, respectively corresponding to the begin and the end of fabrication, are very similar. However, Fig. 10b shows that the microstructure is somewhat different in the middle of the wall, with an additional lightly etched phase. This fairly coarse phase, located on grain boundaries (Fig. 10d), is only present in the middle, which remains above $600{ }^{\circ} \mathrm{C}$ during about 30 minutes. Bhadeshia et al. (1985) observed such a microstructure in low alloy steel welds and identified allotriomorphic ferrite located at prior austenite grain boundaries that may form between $800{ }^{\circ} \mathrm{C}$ and $600{ }^{\circ} \mathrm{C}$ during cooling. It grows thanks to the movement of planar grain boundaries between ferrite and austenite.

A slightly blue phase with polygonal shape was observed (Fig. 11a) after nital etching and X-ray diffraction measurements were performed from the bottom to the top of the wall, revealing the presence of austenite peaks in the upper part (Fig. 11c). There was no retained austenite at the bottom of the wall $(20<\mathrm{Z}<30 \mathrm{~mm})$ whereas measurements between 30 and $190 \mathrm{~mm}$ gave a volume fraction ranging from 2 to $8 \%$. Colour reagents such as Le Pera and Klemm can also be used to identify the different phases, as mentioned by Radwański et al. (2015) for complex C-Mn steel microstructures or Vander Voort (2004): ferrite and martensite are coloured whereas austenite remains unetched. The result on our ER100 C-Mn steel wall can be clearly seen in Fig. 11b where retained austenite appears in white, corresponding to the slightly blue phase in Fig. 11a, the presence of which is totally unexpected since high strength steel consumables such as ER100 are designed to produce 


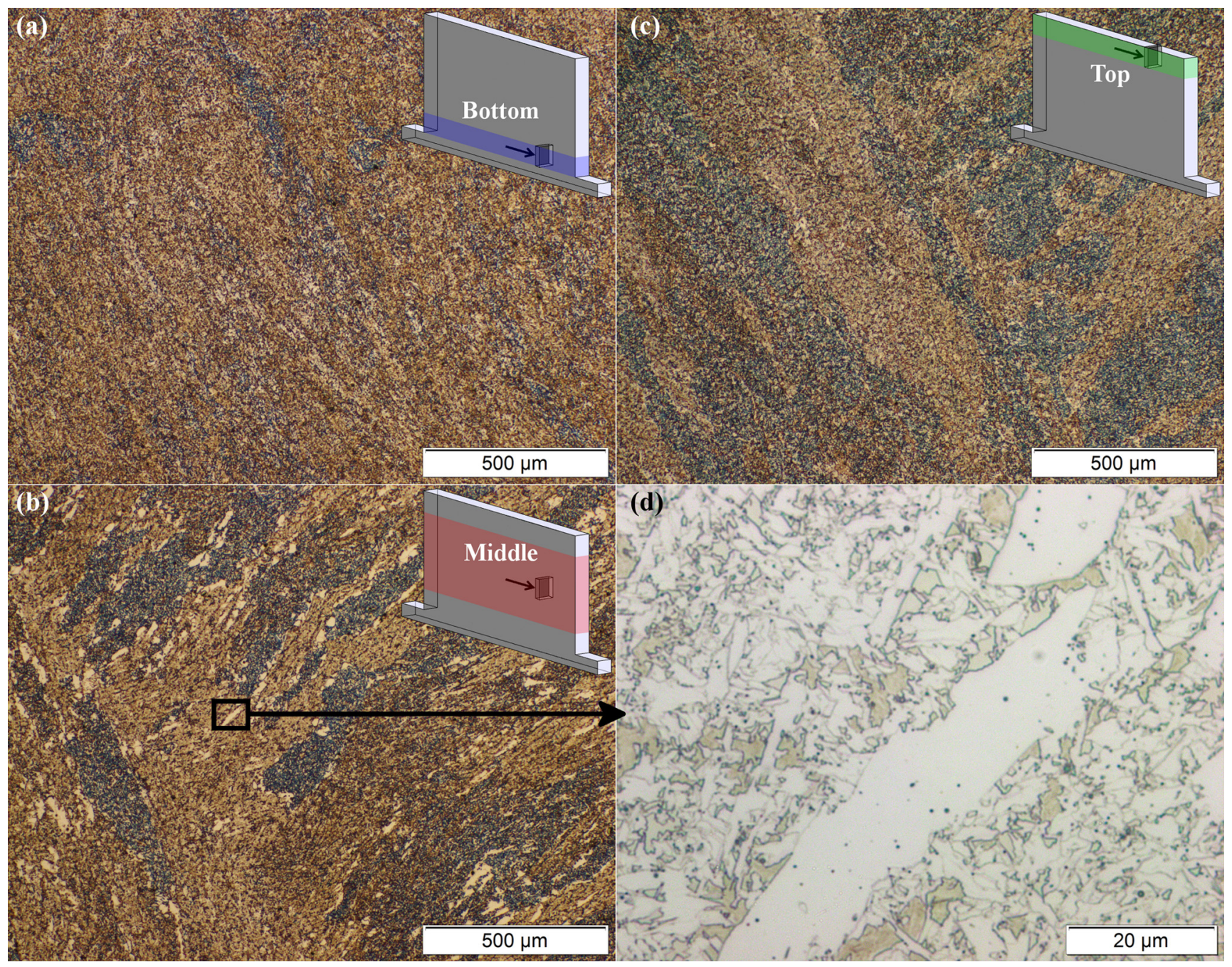

Fig. 10. Microstructure on cross section at low magnification at (a) the bottom, (b) the middle and (c) the top of the wall, (d) higher magnification of (b) showing allotriomorphic ferrite. Etchant: nital.

a microstructure with high mechanical properties and no retained austenite after welding (indeed, a high temperature heat treatment removing retained austenite would also decrease the sought strength). In the case of AM, the mechanisms are different with no dilution effects except at the very bottom of the wall, where thermal cycles are closer to those encountered during welding and no retained austenite was found.

In order to understand why retained austenite forms in ER100 walls, thermodynamic simulations were carried out with Thermo-Calc (version 3.0.1.1, TCFE 7 database) considering equilibrium and Scheil calculations: they both imply perfect element mixing in the liquid, with and without diffusion in the solid phases, respectively. For both cases, no phase was suppressed. The equilibrium calculations were performed because the deposited material experiences numerous heating cycles and a low cooling rate, which tends to produce microstructures close to equilibrium. However, previous works carried out in the field of surfacing showed that equilibrium may only be reached in the case of welding and allied processes for material exposure at high temperature for very long period. This is why Scheil simulations were carried out as well (Scandella and Scandella, 2004). As can be seen in Fig. 12a, alloy solidification is expected to start at about $1510{ }^{\circ} \mathrm{C}$ with the formation of a large amount of $\delta$ ferrite (up to $75 \mathrm{~mol} . \%$ forms in a small range of temperature), which then transforms into austenite and subsequently into $\alpha$ ferrite below $800^{\circ} \mathrm{C}$. Fig. $12 \mathrm{~b}$ shows the alloy solidification under non-equilibrium conditions: about $70 \mathrm{~mol} . \% \delta$ ferrite forms between $\approx$ $1510^{\circ} \mathrm{C}$ and $\approx 1485^{\circ} \mathrm{C}$, which then transforms into austenite below that temperature. Titanium and molybdenum rich MC type carbides are expected to precipitate towards the end of solidification, between about $1350{ }^{\circ} \mathrm{C}$ and $1200^{\circ} \mathrm{C}$. The alloy solidification is therefore as follows:

$\mathrm{L} \stackrel{1510^{\circ} \mathrm{C}}{\rightarrow} \mathrm{L}+\delta \stackrel{1485^{\circ} \mathrm{C}}{\rightarrow} \mathrm{L}+\gamma \stackrel{1350^{\circ} \mathrm{C}}{\rightarrow} \mathrm{L}+\gamma+\mathrm{MC}$

As can be seen in Fig. 12c, substantial amounts of Mn, Mo and C are rejected in the liquid. The chemical composition of the remaining liquid close to the solidus is (neglecting minor elements) $\mathrm{Fe}-2.9 \mathrm{C}-1.7 \mathrm{Si}$ $5.2 \mathrm{Mn}-5.2 \mathrm{Mo}-2.1 \mathrm{Ni}-0.3 \mathrm{Cr}$, wt.\%. With such a high amount of carbon and despite the presence of ferrite formers (especially Mo), it is highly likely that the liquid close to grain boundaries forms austenite that does not transform upon cooling.

Fig. $12 \mathrm{~d}$ shows that austenite is also gradually enriched with high amounts of $\gamma$ stabilizers between $1485^{\circ} \mathrm{C}$ and $1200^{\circ} \mathrm{C}$, in particular Mn and $\mathrm{Ni}$, and to a lesser degree with carbon which does nevertheless reach $1 \mathrm{wt} \%$ close to the solidus. Ferrite stabilizers are also present, mainly $\mathrm{Si}$, Mo and $\mathrm{Cr}$. An easy way to assess the propensity to stabilize austenite forming in the $\mathrm{L}+\gamma+\mathrm{MC}$ domain is to calculate the theoretical Ms temperature using Andrews' formula (Andrews, 1965):

Ms $\left({ }^{\circ} \mathrm{C}\right)=539-423 \mathrm{C}-30.4 \mathrm{Mn}-17.7 \mathrm{Ni}-12.1 \mathrm{Cr}-7.5 \mathrm{Mo}(w \mathrm{wt} . \%)$

which is valid for $0.11<\mathrm{C}<0.55, \quad 0.2<\mathrm{Mn}<1.67$, $0.11<\mathrm{Si}<1.74$, Ni $<5-\mathrm{Cr}<3.3$ and $0<\mathrm{Mo}<1$ (wt.\%). 

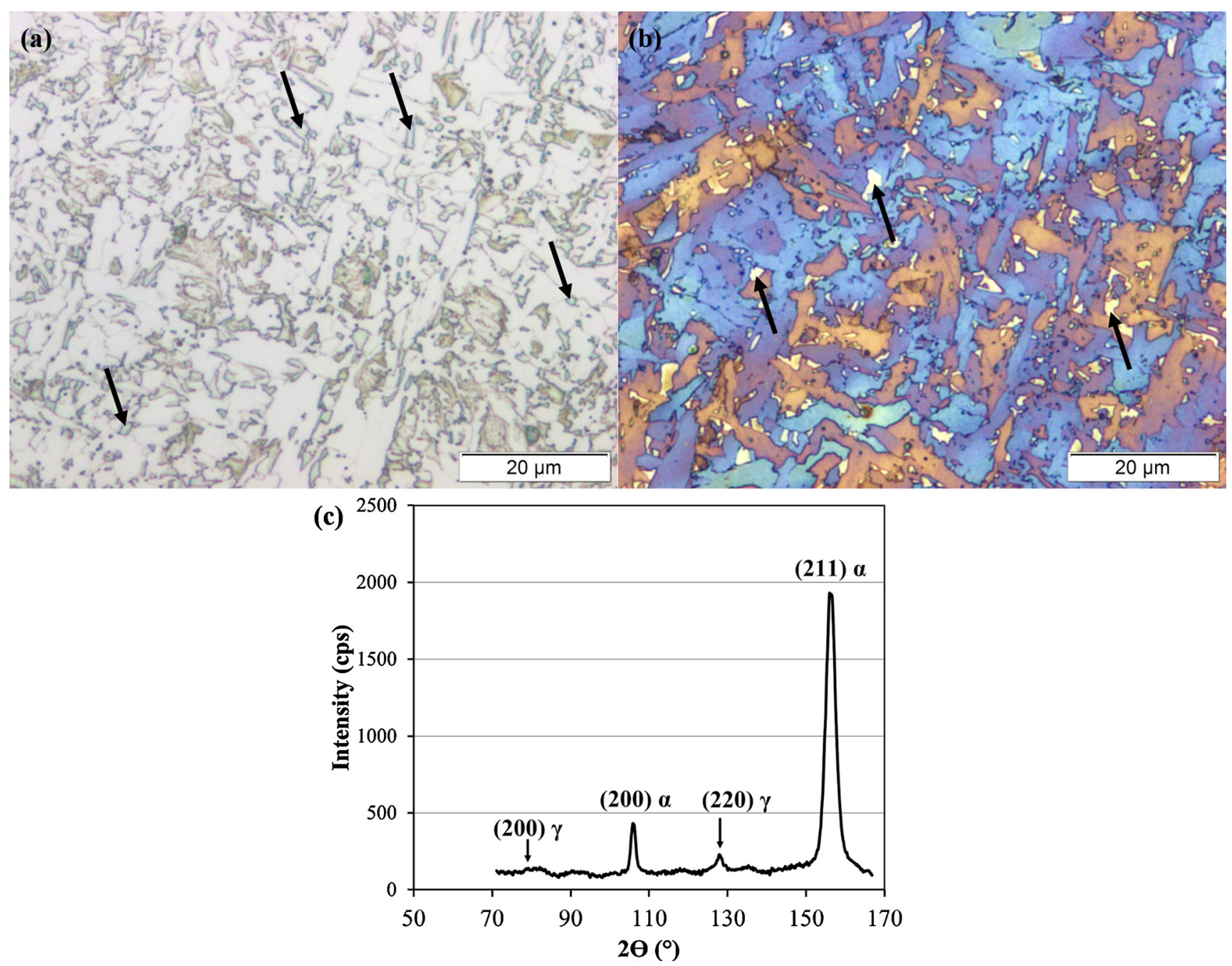

Fig. 11. Retained austenite highlighting: (a) 3\% nital etching, (b) Klemm colour etching, (c) X-ray diffraction peaks.

Obviously, given the highly alloyed computed chemical composition of austenite, Ms temperature values must be considered carefully as the calculations are performed outside the range for which the formula has been experimentally validated. Calculations give a Ms of $428^{\circ} \mathrm{C}$ for an austenite composition of $\mathrm{Fe}-0.07 \mathrm{C}-1.48 \mathrm{Mn}-0.44 \mathrm{Si}-1.72 \mathrm{Ni}$ $0.25 \mathrm{Cr}-0.40 \mathrm{Mo}$, wt. $\%$ at $1485^{\circ} \mathrm{C}$ and $-77^{\circ} \mathrm{C}$ for an austenite composition of $\mathrm{Fe}-1 \mathrm{C}-4.30 \mathrm{Mn}-2.15 \mathrm{Si}-2.80 \mathrm{Ni}-0.29 \mathrm{Cr}-1.26 \mathrm{Mo}$, wt. $\%$ at $1200{ }^{\circ} \mathrm{C}$. It can be concluded that both the austenite forming from the liquid present at the end of solidification and the last austenite forming close to the solidus may produce retained austenite at room temperature.

\subsubsection{Wall microstructure after heat treatment}

The heat treatment used for one of the walls was $600{ }^{\circ} \mathrm{C}$ for $4 \mathrm{~h}$ with heating and cooling at $50{ }^{\circ} \mathrm{C} / \mathrm{h}$. Three zones (bottom, middle, top) were observed as for the as deposited wall. Optical microscope microstructural observations revealed the presence of coarse allotriomorphic ferrite grains: they seem not to be affected by the heat treatment since their localisation along the wall height (in the middle but not at the bottom or at the top of the wall) is similar to that of the as deposited wall.

X-ray diffraction measurements were also performed from the bottom to the top of the wall but no austenite peak was observed. Colour etched microstructure presented in the Fig. 13 show the difference of the microstructure at the top of the as deposited wall (Fig. 13a) and of the heat-treated wall (Fig. 13b). In accordance with X-ray diffraction results, no retained austenite was observed in the heattreated wall. Since the retained austenite is an unstable phase at room temperature, the heat treatment would have destabilised it and transformed into ferrite and iron carbides.

\subsection{Mechanical properties}

\subsubsection{Hardness}

Hardness mappings are shown in Fig. 14. The substrate hardness is around $180 \mathrm{HV} 2$ whereas the wall hardness varies from about 220 to $280 \mathrm{HV} 2$ with some higher values between about 20 and $30 \mathrm{~mm}$. The higher values at the bottom are due to lower thermal conditions and the dilution with the substrate. Despite the heat treatment leading to the transformation of retained austenite, the two hardness mappings remain nearly similar. These results show a good homogeneity along the wall height, which is interesting regarding the final mechanical properties of an industrial part and considering that the substrate will be removed.

\subsubsection{Tensile properties}

Tensile properties of the as deposited and heat-treated walls are shown in Fig. 15 (engineering values). Results are given for all horizontal $(\mathrm{H})$ and vertical $(\mathrm{V})$ specimens shown in Fig. 5 to check for mechanical anisotropy. For both walls, $\mathrm{H}$ and $\mathrm{V}$ specimens show almost identical Yield strength (Ys), tensile strength (Ts) and strain to fracture (A\%), meaning that tensile properties are isotropic considering the 

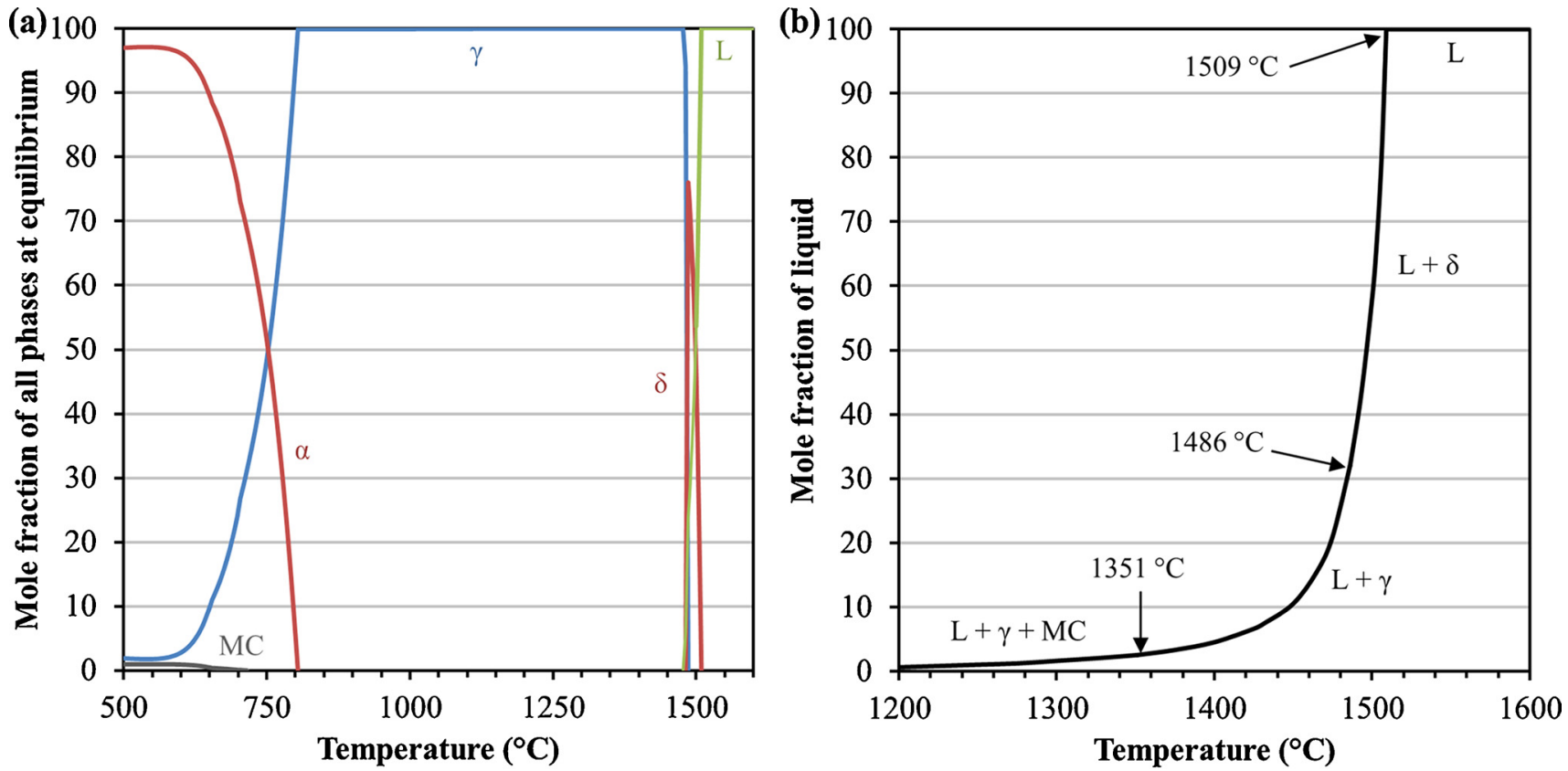

(c)

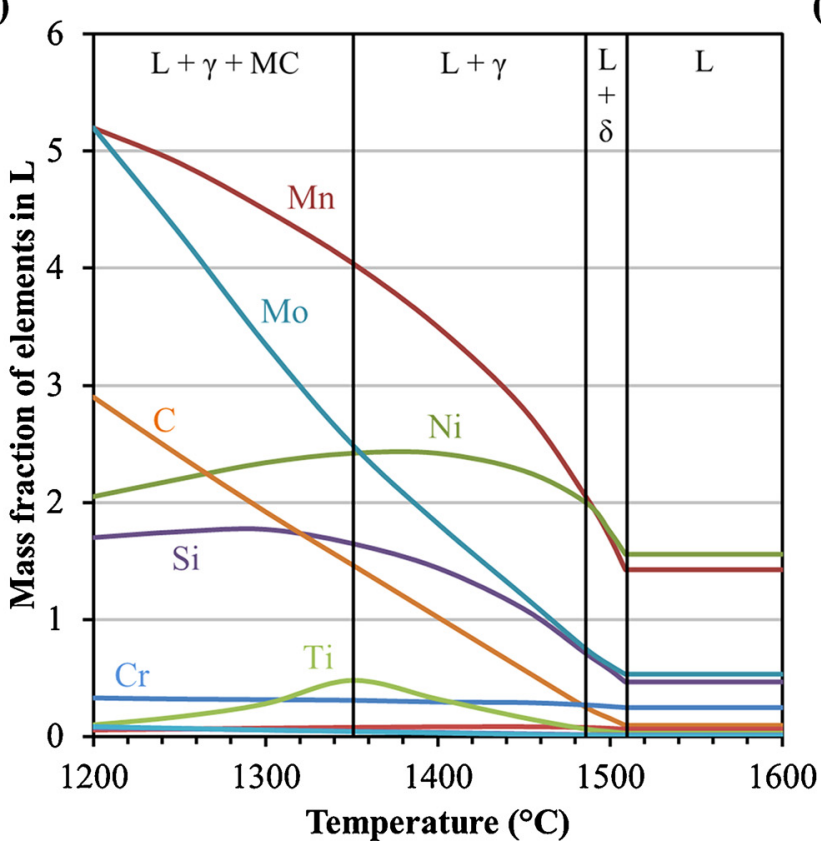

(d)

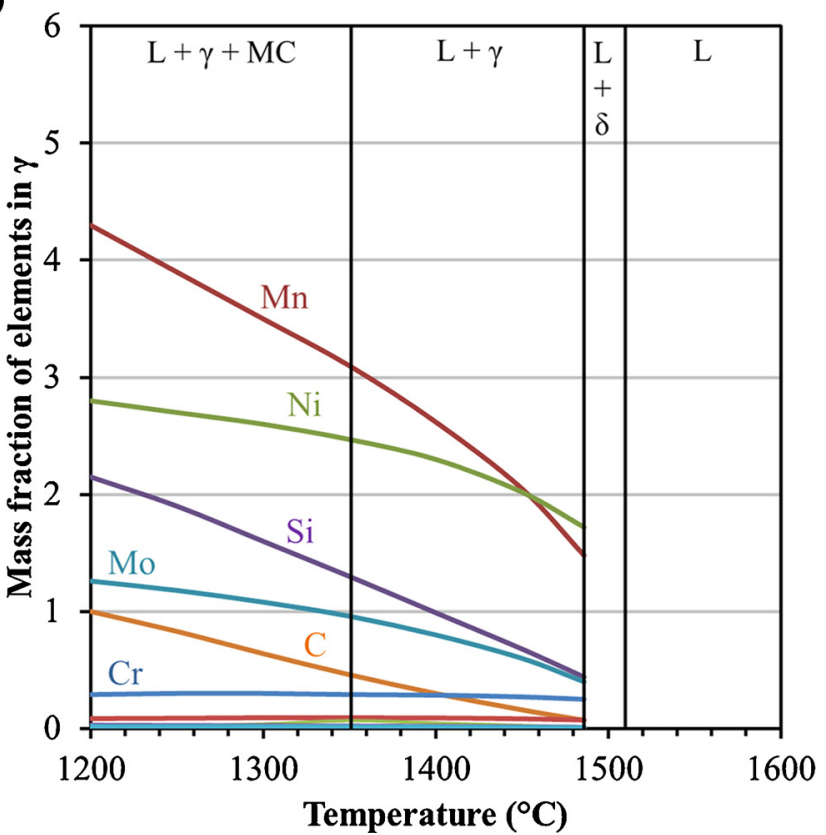

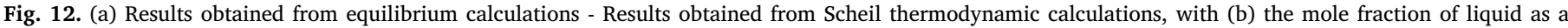
function of temperature and (c), (d) the mass fraction of chemical elements (as a function of temperature) in the liquid and austenite, respectively.

manufacturing conditions.

The main effect of the heat treatment on tensile properties is the improvement of the mean Ys from 520 to $600 \mathrm{MPa}$. As discussed before, the presence of retained austenite in the as deposited wall and not in the heat-treated one should contribute to this yield strength enhancement. Fig. 16 shows the Ys and the Ts of each $\mathrm{H}$ specimen along the Zaxis for both walls. The presence of retained austenite (only in the as deposited wall) and coarse allotriomorphic ferrite is also represented to evaluate their impact on tensile properties. The presence of coarse allotriomorphic ferrite cannot be linked to the Ts or Ys evolution and should have no influence on tensile properties. However, the evolutions of Ys along Z-axis on both walls are similar, with higher values after heat treatment. The presence of retained austenite on all $\mathrm{H}$ specimens of the as deposited wall confirms that the transformation of retained austenite contributes to the Ys enhancement.
The mechanical properties of the heat-treated wall were compared to those of equivalent wrought steel grades S500 M and P500QL (Table 2). Values for these two steels were obtained from tests certificates considering $20 \mathrm{~mm}$ thick plates. The average yield strength of the heat-treated wall is significantly higher than that of S500 M (about $50 \mathrm{MPa}$ ), but lower than that of P500QL (about $40 \mathrm{MPa}$ ); the average tensile strength is higher than that of $5500 \mathrm{M}$ and P500QL. Strain to fracture has been found to be slightly lower than for S500 M. All these results show the capability of wire-arc AM to produce parts with good tensile properties.

\subsubsection{Toughness}

Impact strength as a function of temperature is shown in Fig. 17 for both as deposited and heat-treated walls. The spread in impact strength values for a given temperature is fairly low. The material toughness 


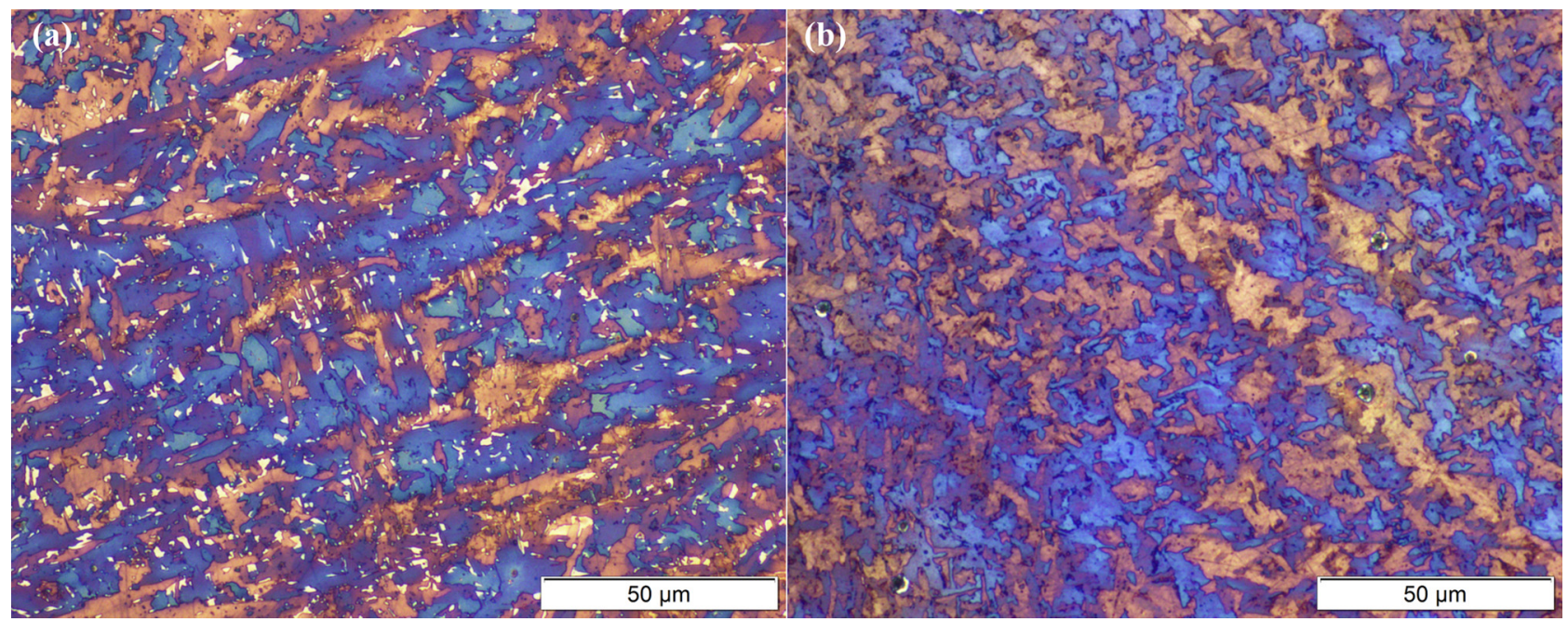

Fig. 13. Colour-etched microstructure with Klemm's reagent: (a) as deposit with retained austenite (white), (b) after heat treatment without retained austenite.
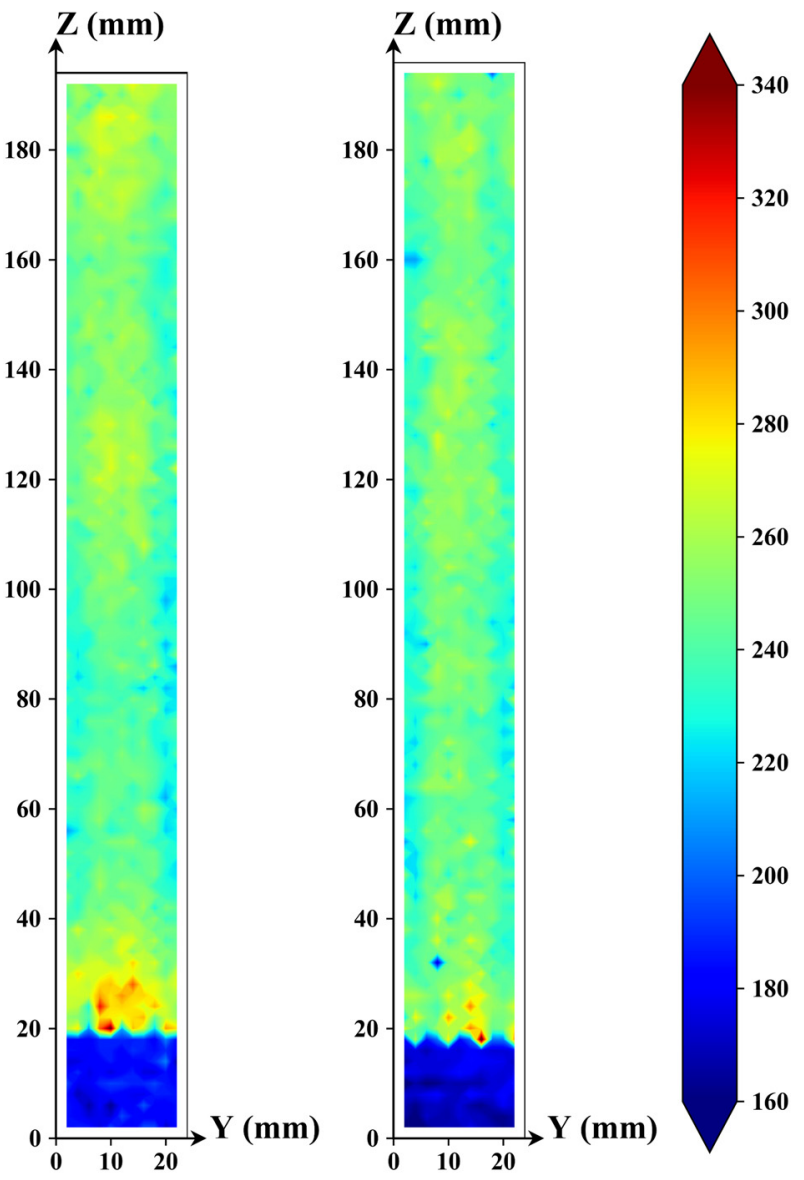

As deposit

After heat treatment

Fig. 14. Hardness mapping (HV2) of walls.

increases slightly (5 to $10 \mathrm{~J}$ ) after heat treatment. The ER100 wire test certificate provides impact strength values of $50 \mathrm{~J}$ at $-60^{\circ} \mathrm{C}$, which is much higher than the values obtained for the wall even after heat treatment. In the case of steel welds, the impact toughness is affected by microstructure as well as oxygen and inclusion content, as shown by (Fattahi et al., 2011): they also mentioned that the presence of coarse allotriomorphic ferrite in steels decreases impact strength, which is consistent with the results obtained in this work since coarse allotriomorphic ferrite is present in the middle of the wall, where the impact test specimens were extracted. Moreover, under welding conditions, heat input and interpass temperature have an effect on the cooling rate and the resulting microstructure; according to the ISO 16834 standard, ER100 certified properties are obtained with an interpass temperature between 120 and $180^{\circ} \mathrm{C}$. In the case of wire-arc $\mathrm{AM}$, no interlayer temperature was set so that it could reach about $750{ }^{\circ} \mathrm{C}$. This major difference between welding and additive manufacturing leads to distinct microstructures and consequently different toughness properties.

\section{Conclusions}

This work illustrates the capability of wire-arc additive manufacturing to produce large parts with a deposition time efficiency close to 1 using high strength steel consumables. Thermal behavior, microstructure and mechanical properties were investigated. The main results are:

- The temperature variations of the material during wall manufacturing are complex and linked to the deposit strategy. Using a deposition time efficiency close to 1 does not give the part enough time to cool down, which leads to a very high temperature at the top of the wall (around $750{ }^{\circ} \mathrm{C}$ ). The similar temperature evolution of both walls confirmed that the process is reproducible.

- The thermal cycles in the wall were classified in three different zones which lead to differences in microstructure: a first zone at the bottom of the wall which does not get very hot and presents neither coarse allotriomorphic ferrite nor retained austenite, a zone in the middle of the wall which gets very hot (above $600^{\circ} \mathrm{C}$ ) for a long time (30 minutes) that presents coarse allotriomorphic ferrite and retained austenite, and last deposited layers which also get very hot but do not remain above $600^{\circ} \mathrm{C}$ during a long time and present retained austenite.

- The toughness result is lower than expected and seems to be explained by the presence of coarse allotriomorphic ferrite grains.

- Tensile properties are isotopic with good values comparable to steel grades S500. The post fabrication heat treatment improves the yield stress through the transformation of retained austenite and the relief of residual stress.

\section{Declaration of Competing Interest}




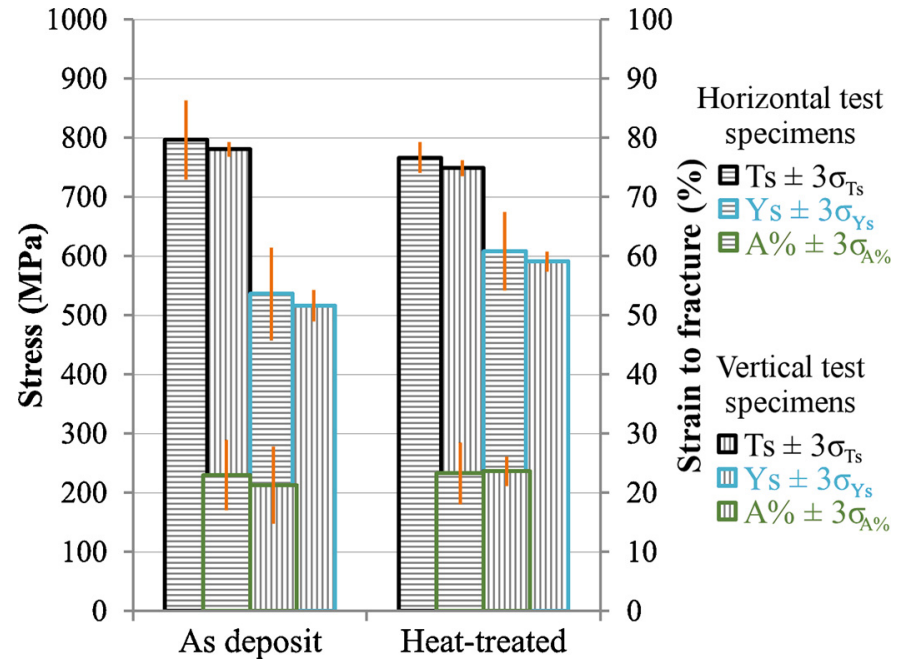

Fig. 15. Tensile properties obtained for as deposited and heat-treated walls (engineering values).

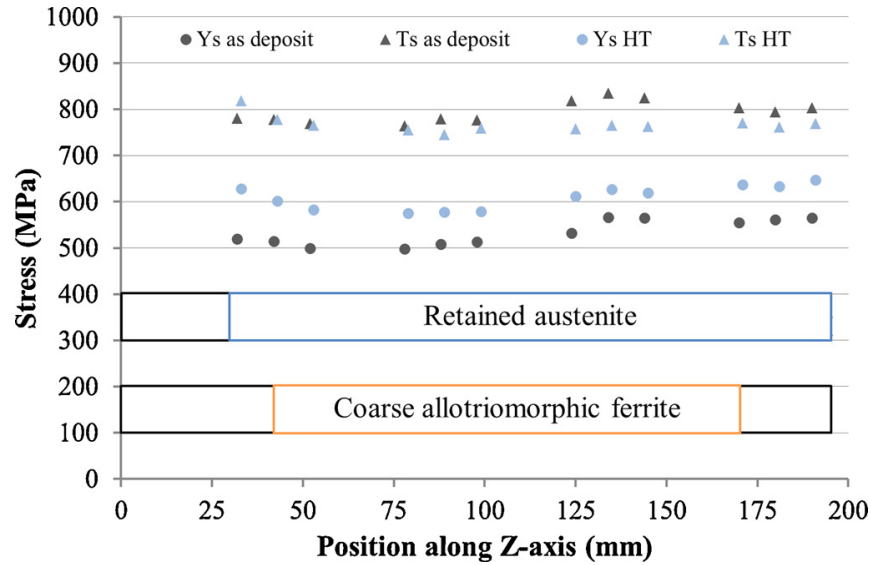

Fig. 16. Evolution of Ys and Ts along Z-axis for horizontal specimens.

Table 2

Mean values of Ys, Ts and A\% forER100 after heat treatment (average values considering both directions) as well as S500 M and P500QL wrought materials.

\begin{tabular}{llll}
\hline & Ys (MPa) & Ts (MPa) & A\% \\
\hline ER100 HT & 600 & 760 & 23 \\
S500M & $545(-10 \%)$ & $670(-13 \%)$ & $25(+8 \%)$ \\
P500QL & $645(+7 \%)$ & $705(-8 \%)$ & $23(0 \%)$ \\
\hline
\end{tabular}

\section{CRediT authorship contribution statement}

Clément Bourlet: Investigation, Validation, Writing - original draft. Sandra Zimmer-Chevret: Resources, Writing - review \& editing. Raphaël Pesci: Resources, Writing - review \& editing. Régis Bigot: Resources, Writing - review \& editing. Aurélien Robineau: Funding acquisition, Resources, Writing - review \& editing. Fabrice Scandella: Funding acquisition, Resources, Writing - review \& editing.

\section{Acknowledgements}

The authors want to thank Institut de Soudure for the financial support, M. Roussel of Manoir Industries Pitres (France) for his scientific and technical support about ThermoCalc simulations, as well as all the technical staff at ENSAM-Arts et Métiers ParisTech, in particular M. Schumacker and M. Fendler, for their support during thermal acquisition and heat treatment.

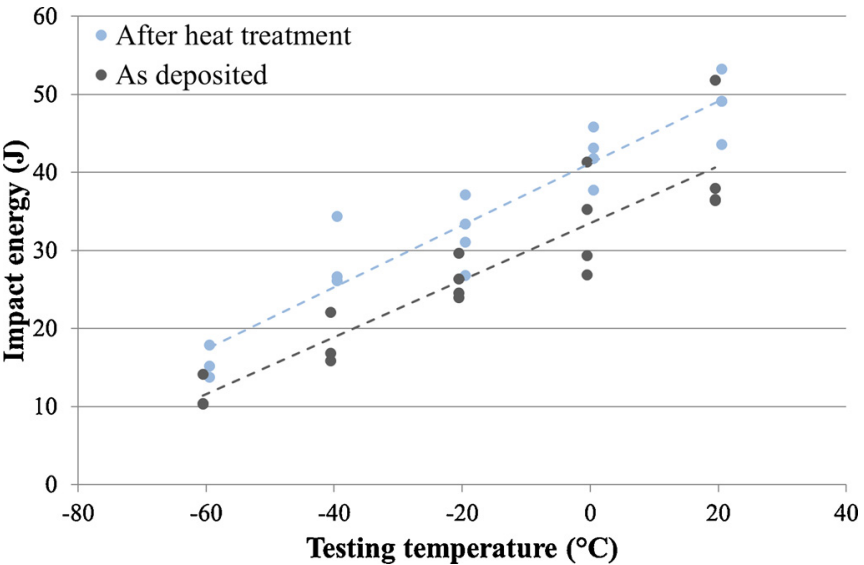

Fig. 17. Impact strength as the function of temperature for the as deposited and heat-treated walls.

\section{References}

Andrews, K.W., 1965. Empirical formulae for the calculation of some transformation temperatures. J. Iron Steel Inst. 203, 721-727.

Appleyard, D., 2012. Welding Pelton Runners. HRW-Hydro Rev, Worldw.

ASTM E975-13, 2013. Standard practice for X-ray determination of retained austenite in steel with near random crystallographic orientation. https://doi.org/10.1520/ E0975-13.

Bai, J.Y., Fan, C.L., Lin, S. b., Yang, C.L., Dong, B.L., 2016. Effects of thermal cycles on microstructure evolution of 2219-Al during GTA-additive manufacturing. Int. J. Adv. Manuf. Technol. 87, 2615-2623. https://doi.org/10.1007/s00170-016-8633-1.

Bhadeshia, H.K.D.H., Svensson, L.-E., Gretoft, B., 1985. The influence of alloying elements on the formation of allotriomorphic ferrite in low-alloy steel weld deposits. J. Mater. Sci. Lett. 4, 305-308. https://doi.org/10.1007/BF00719798.

Caballero, A., Ding, J., Ganguly, S., Williams, S., 2019. Wire + Arc Additive Manufacture of 17-4 PH stainless steel: effect of different processing conditions on microstructure, hardness, and tensile strength. J. Mater. Process. Technol. 268, 54-62. https://doi. org/10.1016/j.jmatprotec.2019.01.007.

Chen, X., Li, J., Cheng, X., He, B., Wang, H., Huang, Z., 2017. Microstructure and mechanical properties of the austenitic stainless steel 316L fabricated by gas metal arc additive manufacturing. Mater. Sci. Eng. A 703, 567-577. https://doi.org/10.1016/j. msea.2017.05.024.

Ding, D., Pan, Z., Cuiuri, D., Li, H., 2015a. Wire-feed additive manufacturing of metal components: technologies, developments and future interests. Int. J. Adv. Manuf. Technol. 81, 465-481. https://doi.org/10.1007/s00170-015-7077-3.

Ding, D., Pan, Z., Cuiuri, D., Li, H., 2015b. A multi-bead overlapping model for robotic wire and arc additive manufacturing (WAAM). Robot. Comput. Integr. Manuf. 31, 101-110. https://doi.org/10.1016/j.rcim.2014.08.008.

Ding, J., Colegrove, P., Mehnen, J., Ganguly, S., Sequeira Almeida, P.M., Wang, F., Williams, S., 2011. Thermo-mechanical analysis of Wire and Arc Additive Layer Manufacturing process on large multi-layer parts. Comput. Mater. Sci. 50, 3315-3322. https://doi.org/10.1016/j.commatsci.2011.06.023.

Fattahi, M., Nabhani, N., Vaezi, M.R., Rahimi, E., 2011. Improvement of impact 
toughness of AWS E6010 weld metal by adding TiO2 nanoparticles to the electrode coating. Mater. Sci. Eng. A 528, 8031-8039. https://doi.org/10.1016/j.msea.2011. 07.035.

Gu, J., Cong, B., Ding, J., Williams, S.W., Zhai, Y., 2014. Wire + Arc Additive Manufacturing of aluminium. SFF symposium. 451-458.

Hirtler, M., Jedynak, A., Sydow, B., Sviridov, A., Bambach, M., 2018. Investigation of microstructure and hardness of a rib geometry produced by metal forming and wirearc additive manufacturing. MATEC Web of Conferences. https://doi.org/10.1051/ matecconf/201819002005.

Lin, J.J., Lv, Y.H., Liu, Y.X., Xu, B.S., Sun, Z., Li, Z.G., Wu, Y.X., 2016. Microstructural evolution and mechanical properties of Ti-6Al-4V wall deposited by pulsed plasma arc additive manufacturing. Mater. Des. 102, 30-40. https://doi.org/10.1016/j. matdes.2016.04.018.

Martina, F., Ding, J., Williams, S., Caballero, A., Pardal, G., Quintino, L., 2018. Tandem Metal Inert Gas process for high productivity Wire Arc Additive Manufacturing in stainless steel. Addit. Manuf. 25, 545-550. https://doi.org/10.1016/j.addma.2018. 11.022 .

Martina, F., Williams, S., 2015. Wire + arc additive manufacturing vs. traditional machining from solid: a cost comparison.

Qi, Z., Cong, B., Qi, B., Zhao, G., Ding, J., 2018. Properties of wire + arc additively manufactured 2024 aluminum alloy with different solution treatment temperature. Mater. Lett. 230, 275-278. https://doi.org/10.1016/j.matlet.2018.07.144.

Scandella, F., Scandella, R., 2004. Development of hardfacing material in Fe-Cr-Nb-C system for use under highly abrasive conditions. Mater. Sci. Technol. 20, 93-105. https://doi.org/10.1179/026708304225011234.

Shen, C., Pan, Z., Ding, D., Yuan, L., Nie, N., Wang, Y., Luo, D., Cuiuri, D., van Duin, S., Li,
H., 2018. The influence of post-production heat treatment on the multi-directional properties of nickel-aluminum bronze alloy fabricated using wire-arc additive manufacturing process. Addit. Manuf. 23, 411-421. https://doi.org/10.1016/j.addma. 2018.08.008.

Tabernero, I., Paskual, A., Álvarez, P., Suárez, A., 2018. Study on Arc Welding Processes for High Deposition Rate Additive Manufacturing. Procedia CIRP 68, 358-362. https://doi.org/10.1016/j.procir.2017.12.095.

Vander Voort, G.F., 2004. Color Metallography. ASM Handbook Volume 9 Metallography and Microstructures.

Wang, F., Williams, S., Colegrove, P., Antonysamy, A.A., 2013. Microstructure and mechanical properties of wire and arc additive manufactured Ti-6Al-4V. Metall. Mater. Trans. A 44, 968-977. https://doi.org/10.1007/s11661-012-1444-6.

Williams, S.W., Martina, F., Addison, A.C., Ding, J., Pardal, G., Colegrove, P., 2016. Wire + Arc Additive Manufacturing. Mater. Sci. Technol. 32, 641-647. https://doi.org/ 10.1179/1743284715Y.0000000073.

Wu, B., Ding, D., Pan, Z., Cuiuri, D., Li, H., Han, J., Fei, Z., 2017. Effects of heat accumulation on the arc characteristics and metal transfer behavior in wire arc additive manufacturing of Ti6Al4V. J. Mater. Process. Technol. 250, 304-312. https://doi. org/10.1016/j.jmatprotec.2017.07.037.

Xu, X., Ding, J., Ganguly, S., Williams, S., 2019. Investigation of process factors affecting mechanical properties of INCONEL 718 superalloy in wire + arc additive manufacture process. J. Mater. Process. Technol. 265, 201-209. https://doi.org/10.1016/j. jmatprotec.2018.10.023.

Yili, D., Shengfu, Y., Yusheng, S., Tianying, H., Lichao, Z., 2018. Wire and arc additive manufacture of high-building multi-directional pipe joint. Int. J. Adv. Manuf. Technol. 96, 2389-2396. https://doi.org/10.1007/s00170-018-1742-2. 